\title{
Anna María Prat i Trabal (1938-2013)
}

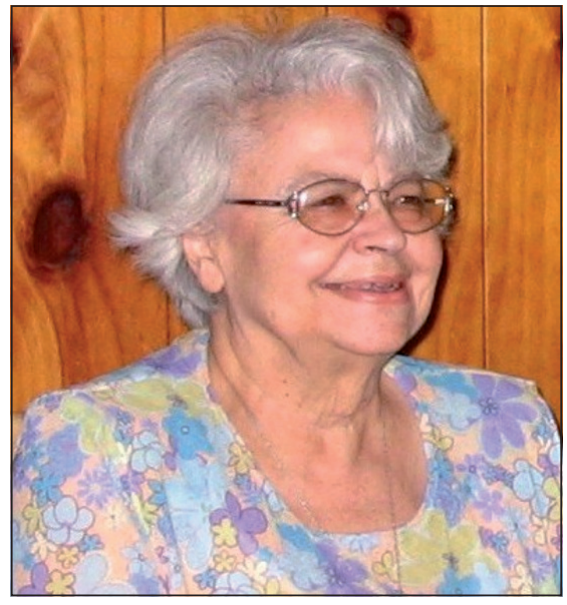

$\mathrm{N}$ o es fácil expresar lo que fue Anna María Prat i Trabal y lo que representó para Chile y la Comisión Nacional de Investigación Científica y Tecnológica, CONICYT, institución que acogió en Chile durante 40 fructíferos años, a nuestra querida jefa, amiga, destacada profesional, gran líder en los temas de la bibliotecología, información científica y documentación, y por sobre todo una gran persona, siempre actualizada, creativa e innovadora y muy carismática.

Anna María ingresó a CONICYT en 1968 cuando era bibliotecaria del Centro Nacional de Información y Documentación, más conocido como CENID, centro que fue trasladado desde donde se originó -el Consejo de Rectores de las Universidades Chilenas- a esta nueva institución, transformándose luego en el Departamento de Información de CONICYT. La labor de Anna María en este departamento que dirigió por más de 25 años fue inconmensurable, principalmente por su profesionalismo, sabiduría, inteligencia, cultura, amor y dedicación que desplegaba en cada una de las actividades en que participaba y emprendía. Logró formar un gran equipo de trabajo en este departamento, muy consolidado y siempre unido, así como ella sabía hacer, con mucha presencia, autoridad y carisma, enseñando al mismo tiempo a hacer las cosas bien, con las puertas siempre abiertas al diálogo, siempre dispuesta a solucionar dudas o problemas que se presentaran.

Entre sus variadas actividades son muy notables aquellas desarrolladas a la enseñanza de la bibliotecología, tanto en Chile como a nivel iberoamericano y en favor de las revistas científicas chilenas, liderando al mismo tiempo un sistema de información científica a nivel nacional que involucraba a universidades, institutos de investi- gación y sociedades científicas entre otras instituciones. Realizó un gran aporte al desarrollo e instauración en CONICYT de los llamados "Cursos de Entrenamiento", para la actualización y aprendizaje de diferentes aspectos en el ámbito de la bibliotecología, documentación e información, con presencia de destacados profesionales tanto nacionales como extranjeros, quienes dictaban los cursos, actividades que duraron hasta la década de los 80 ; impulsora y gestora junto a otras destacadas profesionales de la época, del Catálogo Colectivo Nacional de Publicaciones Periódicas; impulsora de la iniciativa de creación del Fondo de Publicación de Revistas Científicas Chilenas que data desde 1988; activa participante en redes nacionales, regionales e internacionales de información, a través de la coordinación de los llamados, en esos años, "focos nacionales" gestionados por el Departamento de Información de CONICYT, entre éstos, PGI (Programa General de Información de la Unesco) llegando a ser su vicepresidenta; Centro Nacional de ISSN (International Standard Serial Number) desde 1982, llegando a incorporarse a la directiva del Centro Internacional de ISSN, hace pocos años atrás; red INFOTERRA de medio ambiente; representante de FIDCLA (Federación Internacional de Documentación para América Latina y El Caribe); Red de Indicadores Científicos (RICYT), entre otros. Con la creación de la Red Universitaria Nacional (REUNA) en el año 1986 y posteriormente en 1992 con el aporte de CONICYT y otros organismos se logra conectar Chile a Internet, donde Anna María participó con su entusiasmo de siempre para tener en CONICYT un "gopher" y posteriormente un sitio web a fin de dar a conocer la actividad de la institución, así como, la actividad científica y tecnológica, y producción científica del país. En este 
ámbito de la producción científica trabajó arduamente para proporcionar a los investigadores y académicos sus datos de producción científica, así como indicadores de ciencia y tecnología junto con otros colaboradores de la institución.

Al crearse, en la década de los 90, la Red Nacional de Información Bibliográfica (RENIB), siempre bajo el alero del Departamento de Información, se crea e inaugura en el año 1999 el primer Catálogo Colectivo Nacional de Publicaciones Periódicas en Línea, para la búsqueda y localización de revistas en las bibliotecas de las diferentes universidades chilenas. Tuvo también una destacada y activa participación en LATINDEX (Sistema Regional de Información en Línea para Revistas Científicas de América Latina, el Caribe, España y Portugal), desde sus inicios en los años 1997-1998.

Anna María entre sus diferentes viajes para participar en reuniones internacionales en representación de la institución y del país tuvo reiteradas oportunidades para intercambiar y compartir conocimiento y nuevas ideas con diversos profesionales y especialistas, sabiendo rescatar con esa claridad de pensamiento, virtud que la caracterizaba y destacaba, aquellos proyectos o buenas ideas a fin de replicarlas o aplicarlas posteriormente en Chile, así surgió la propuesta de implantar en Chile la metodología SciELO (Scientific Electronic Library On Line) proyecto diseñado y creado en Brasil e iniciado en 1997. Presentó este proyecto a las autoridades de CONICYT en 1998 y luego de ser aceptado, se logró a mediados de Octubre de ese mismo año dar inicio a SciELO Chile y a fines de año se hace visible con las tres primeras revistas científicas nacionales. SciELO surge como modelo para la publicación cooperativa de revistas científicas electrónicas disponibles en Internet, contando entre sus objetivos, dar visibilidad y acceso universal a las revistas científicas nacionales y sus publicaciones, muchas de ellas formando parte del conocimiento comúnmente llamado "ciencia perdida". Para dar inicio a SciELO Chile, Anna María congrega primeramente a un grupo de editores de revistas, dando a conocer las características y ventajas significativas para la revista y los invita a participar en este proyecto, a partir de esta etapa realiza una actividad profunda de asesoramiento y ayuda a un vasto número de editores de revistas científicas chilenas, para mejorar la calidad editorial y de contenido de las revistas, actividad que se hace extensible a otros países de América Latina.
En el año 2000 Anna María deja la dirección del Departamento de Información y continúa como asesora de la presidencia de CONICYT, logrando entre sus actividades finales en CONICYT, la activa participación para gestionar y formar CINCEL, Consorcio para el Acceso a la Información Científica Electrónica, facilitando el acceso a revistas científicas internacionales y a otros recursos de información, principalmente para las instituciones de educación superior.

Seguramente se me escapan varios otros hechos en la trayectoria de Anna María en el Departamento de Información, sin embargo, creo que ella me diría: "no importa, la próxima vez será, está lo que tiene que estar y está bien así”.

Anna María siempre fue una persona comprensiva, una persona preocupada por las personas que la rodeaban y trabajaban con ella, dejando siempre una huella de enseñanza y aprendizaje que nos enriquecía día a día para ser mejores, principalmente en sus conversaciones de la mañana con un café y en las horas de almuerzo que compartimos con ella junto con otros queridos amigos, amigas y profesionales de CONICYT durante varias décadas, entre estas amistades queridas no puedo dejar de nombrar a María Isabel Oyarzún (QEPD) y a mi querida amiga María Cecilia Mosso (QEPD) con quienes trabajamos en diferentes proyectos de información. Pocos días antes del fallecimiento de Anna María acaecido el 6 de enero de 2013, hicimos recuerdos juntas.

Estoy muy agradecida de Dios de haberme permitido y dado la oportunidad de conocer a Anna María, ella me enseñó muchísimo y supo valorar la entrega, el cariño y responsabilidad con que trabajamos en el Departamento confiando plenamente en el trabajo que hacíamos.

A Anna María le debemos mucho, y termino dándole gracias infinitas por todo lo que nos transmitió, enseñó y ayudó. La echaremos de menos y la tendremos siempre presente. Con seguridad se ganó un lugar en el Cielo y seguirá colaborando en el Reino de Dios.

Marcela Aguirre Coordinadora de SciELO Chile Programa de Información Cientifica CONICYT

6 de enero, 2013 